\title{
Electroacoustic Feedback and the Emergence of Sound Installation: Remarks on a line of flight in the live electronic music by Alvin Lucier and Max Neuhaus
}

\author{
MATTHIEU SALADIN \\ Université Paris 8 (UFR Arts, Philosophie, Esthétique), 2 Rue de la Liberté, 93526 Saint-Denis, France \\ Email: matthieu.saladin@univ-paris8.fr
}

\begin{abstract}
Reflecting upon Max Neuhaus's and Alvin Lucier's first electronic works on electroacoustic feedback, I will consider how their research into live electronic music, meant to be performed on stage, announced a whole other form of creation, which was paradoxically emancipated from the concert hall and essential to the emergence of sound art: sound installations. If both musicians first appropriated the electronic medium for its possibilities in sound transformation, it appears that these experimentations, and more precisely those using feedback, quickly extended into areas other than research on tone and the live dimension of electronic performances. Indeed, electroacoustic feedback, as a phenomenon of retroaction, goes beyond the mere relationship to the instrument: by manifesting itself in the looping of the electroacoustic chain (microphoneamplification-speakers), it straightaway inscribes the electronic device in a spatial dimension that is linked to the propagation of sound. By analysing Neuhaus's and Lucier's first experiments with feedback, the specificities of their apparatuses and the experiences they aimed to create and foster, this article wishes to question the role these experiments played in the emergence of both musicians' concern with space, which is at the core of any understanding of their later works. We can then re-read their contribution to the history of live electronic music in the light of both bifurcations and lines of flight inherent in their respective bodies of work, in order to look into the emergence of a certain art of sound installation, in which the liveness of live electronic music, far from being pushed aside, seems to lead into other forms of creation and specific aesthetic questions.
\end{abstract}

\section{INTRODUCTION}

For several hundred years Western music has been based on composition and performance. [...] We have been so concerned with language that we have forgotten how sound flows through space and occupies it. (Lucier 1995a: 416)

Traditionally composers have located the elements of a composition in time. One idea which I am interested in is locating them, instead, in space ... and letting the listener place them in his own time. (Neuhaus 1974)
This article wishes to look into the links that may exist between the experiments in live electronic music carried out by Alvin Lucier and Max Neuhaus in the 1960s and 1970s and their burgeoning interest in an entirely different form of artistic practice: sound installation. There are already a number works on the emergence of sound installation (among others de la Motte-Haber 1999; Gallet 2005; Labelle 2006; Licht 2007, 2009; Ouzounian 2008, 2013), a term that Max Neuhaus claimed he had originally coined in the early 1970s to talk about his work Drive in Music (1967) (Neuhaus 1994a: 42). One of the main achievements of these studies has been to show how this practice was born out of several factors, artistic traditions and aesthetic and cultural concerns, which, however, came together around a common questioning of space (even if the concept of space has been interpreted differently in different discourses and practices).

The history of sound installation was in fact a plural history, well before Drive in Music. It contains the intersection, convergence and intertwining of experimentation in architecture, sound spatialisation, the development of installations in visual art, minimalism and conceptual art and even the beginnings of institutional critique, electroacoustic music, tape music, the alternative staging of certain sound experiments in museum spaces and on to thinking on public space, daily life and the production of social space in the wake of situationism and Henri Lefebvre's theories. It is a rich history spilling out over beyond the topic of this article and which, to put it succinctly, documents a problematisation of sound production, not simply in temporal terms, but above all from the perspective of its inscription in space. As Neuhaus puts it, sound installations are 'sound works without a beginning or an end, where the sounds were placed in space rather than time' (Neuhaus 1994a: 42).

My aim here is not to offer a revision of this history but rather to complexify it somewhat in the light of what seems to me to be one of the conditions of possibility of sound installation - or at least its 
development with Neuhaus and Lucier - and yet remains largely absent from the studies alluded to above, namely the influence of live electronic music and especially experiments with electroacoustic feedback. This hypothesis is rooted in the observation of practices themselves. Indeed it comes out of a consideration of the musical background of some of the key players in the emergence of sound installation such as David Tudor, Max Neuhaus and Alvin Lucier, who all did a lot of live electronic music before exploring what can be seen as sound installation. As Tudor's live electronic music and his early installations are already well documented (Collins 2004; Rogalsky 2013), I am going to focus more on electronic works by Neuhaus and Lucier and their relationship with feedback. This article therefore aims to reconsider their contribution to the history of live electronic music in the light of both bifurcations and 'lines of flight' (Deleuze and Guattari 1975) underlying the particular interest in space which their experiments on feedback testify to. It will then be a question of understanding the new artistic preoccupations arising from their spatial introspections, and also how the latter may have led them incidentally to abandon stage performance in order to adopt a certain approach to sound installation in which the liveness of live electronic music, far from being pushed aside, seems to lead into other forms of creation and specific aesthetic questions. In conclusion I want to isolate how taking this influence of their experiments on feedback into consideration opens the door onto a different vision of the historiography and aesthetic issues specific to the emergence of the new form of sound installation. The concept of emergence is very different from the one of birth. As Ian Hacking has it, 'a birth is without precursors. Emergence is a sudden flowering after almost nothing' (Hacking 2002: 24). So it requires ground that is precisely fertile enough for germination to take place.

\section{THE AESTHETIC ISSUES OF LIVE ELECTRONIC MUSIC}

I will first of all quickly go over the main aesthetic issues surrounding the emergence of live electronics in the wake of pioneering work by John Cage and David Tudor, who very early became interested in the performance of electronic music as well as unheard sound worlds produced by the amplification of various materials through the use of contact microphones.

In the 1960s, live electronics was still a relatively new and promising field of experimentation for young musicians, operating through the miniaturisation of equipment (Emmerson 2007: 115) and taking it from electronic laboratory research and detailed, studio-based study into the realm of live performance (Cox 2002: 36). As Hugh Davies emphasises, 'the instantaneous, real-time transformation by means of electronic equipment during a performance of sounds' (Davies 2002: 26) was one of the main reasons for the popularity of these new practices, just as they were partly related to a desire for interaction with performance (Chion 1982: 15). It was, then, its liveness that interested young musicians such as Musica Elettronica Viva (MEV), Taj Mahal Travellers, AMM, Sonic Arts Union, Gentle Fire and Intermodulation: electronics was being freed from its scientific pomp and challenged against the reality of performance - this desire can also be understood in retrospect and with regard to its immediate context as, as Henri Pousseur says, 'a reaction against a certain rationalism and the excessive hegemony of abstract calculation, speculation and combination, which were increasingly separated from practical and perceptual reality' (Pousseur 1970: 177).

There was also the heuristic dimension of electronic music's sonic possibilities, which offered the promise of new sounds, tones, textures and sound masses. Thus, in 1963, Max Neuhaus used amplification and contact microphones to change the tone of his percussion instruments, in particular working on the feedback. As he noted, inserting percussion into a feedback loop allowed him to obtain 'a complex multi-timbred system of oscillation' instead of the usual shrill feedback sound (Neuhaus 2003). Here the role of contact microphones appeared particularly significant. They were understood and used as a medium of immediate access to material, to its direct manipulation. Attaching several contact microphones to this or that prosaic object allowed one to listen to its interior sound. Alvin Curran remembers the wonder that accompanied their use: 'By amplifying the sounds of glass, wood, metal, water, air and fire we were convinced that we had tapped into the sources of the natural musics of "everything". We were in fact making a spontaneous music which could be said to be coming from "nowhere" and made out of "nothing" all somewhat a wonder and a collective epiphany' (Curran 2000: 177-9). These microphones were solicited for their magnifying effect, understood as an aestheticheuristic procedure. In line with the use of the microphone as an examination device, as initiated by Cage's Cartridge Music (1960), live electronic musicians had recourse to contact microphones connected to an amplification system so as to 'reveal a previously unheard, unsuspected range of sounds, drawn out of hitherto mute or near-mute instruments of whatever nature, bringing about both quantitative and qualitative changes in the materials amplified' (Nyman 1999: 92). Amplification allowed displacements in the relations between objects, whether they be found, deteriorated, or cobbled together, but also in the relations between instruments, varying the angle of listening so as to differently observe what may appear common and without surprise. Beyond the spirit of discovery, the enlarging of the detail and the extirpation of the inaudible strives, 
through the new relations of perception that they engender, to reveal a poetry that breaks directly with the 'monstrous' character, in the Barthian sense, of produced sounds. On the subject of the engraving of plates from Diderot and Alembert's Encyclopedia, Barthes notes that:

the poetic (for the monstrous can only be the poetic) is never established except by a displacement of the level of perception: it is one of the Encyclopedia's great gifts to vary (in the musical sense of the term) the level on which one and the same object can be perceived, thereby liberating the very secrets of form: seen through the microscope, the flea becomes a horrible monster, caparisoned with plates of bronze, armed with steel spines, with the head of a wicked bird, and this monster achieves the strange sublimity of mythological dragons [...] Is poetry not a certain power of disproportion, as Baudelaire saw so well, describing the effects of reduction and focusing that hashish induces?). (Barthes 1980: 36)

This last point highlights another important aspect of this research. The original sound realm offered up by live electronics was also underpinned by the indeterminate character of both the sound situations created and the devices used by the musicians. Live electronics involved using indeterminacy or 'to abandon control' (Toop 2002: 244) so as to disengage from conditioned reflexes and musical habits in favour of experimentation. As Christian Wolff points out, in the research carried out by these musicians, the interest in indeterminacy and the use of live electronics devices seemed to go hand in hand: 'There is certainly a continuity between indeterminacy and live electronics: you can make machines whose effects on the sound are unpredictable (as Mumma does), or you can exploit the characteristics of electricity itself, using feedback or the kinds of fault which develop when you multiply your circuits' (Wolff 1998: 74-6). But it is also the empirical and do-it-yourself nature of circuits and electronic arrangements designed by musicians such as Tudor, Behrman or Mumma that favoured the opening onto indeterminacy. Writing on Cage, Nicolas Collins said that: 'The very instability of the electronics of the time, and the unpredictable output of his repurposed appliances, made technology a critical partner in his experiments in indeterminacy' (Collins 2007: 40). Specifically on feedback, he added: 'Cage's acceptance of electronic accident was a sign of things to come. Feedback became the ur-sound of chance: it erupted whenever composers hooked up sound systems without the benefit of technicians' (Collins 2007: 41). And, as Michael Nyman points out, feedback was 'one of the most straightforward methods of ensuring unpredictability in the performance of live electronic music - a method which exploits the potential of the machines themselves coupled with various simple facts of acoustic life' (Nyman 1999: 99). Feedback, and I will come back to this, became a term that went beyond its direct meaning to go as far as to symbolise all experimental relationships at work in a performance space. In a press kit booklet in 1968, the MEV musicians wrote: 'Electronics are a means: making space itself a living circuit' (MEV 1968).

\section{MAX NEUHAUS'S EXPERIMENTS ON FEEDBACK: FROM RESEARCH INTO TIMBRE TO THE CONCEPTUALISATION OF INSTALLATION}

As I mentioned earlier, in the first half of the 1960s Neuhaus began working on feedback loops that allowed him to transform the tone of his instruments. As a musician, Neuhaus was not initially particularly focused on electronics. With a background as a percussionist, initially attracted by drums in jazz, he discovered and became passionate about avant-garde music during his studies at the Manhattan School of Music, emphasising work on sound rather than on melody and harmony, with percussion instruments becoming for him 'the world of timbre' (Neuhaus 2004). Abandoning his first loves, his favourite composers became Harry Partch, Henry Cowell and Lou Harrison as well as, quickly, the members of the New York School, John Cage, Morton Feldman, Earle Brown and Christian Wolff. Under the influence of Cage and his performances with phonograph cartridges, the electronic medium became part of his work as a percussionist in the early 1960 s as the logical continuation of his experiments on textures and sound matter. Commenting on his early experiments on feedback, he writes: 'I had discovered a means of generating sound which I found fascinating - the creation of an acoustic feedback loop with a percussion instrument inserted inside it' (Neuhaus 2003).

Thus work on sound material initially directed his research, with a version, or rather rereading of Fontana Mix (1958) by John Cage, renamed Fontana Mix Feed by Neuhaus, representing a certain culmination of his work at this time. The musician used a set-up consisting of the looping of an electroacoustic network, combined with timbales: contact microphones were placed on the skins of the instruments to capture their vibrations, which were themselves caused by large speakers placed nearby, through which the vibrations captured by the microphones were played at highvolume, producing feedback modulated by a mixing desk. Cage's composition was not originally written with a view to such a performance. It incorporates a part of the indeterminate notation created in 1958 for Concert for Piano and Orchestra, and includes a set of sheets and transparencies, with curved lines, dots and a grid, inserted as material available to the performer to generate a structure that serves as a canvas for the concert. So Neuhaus used the compositional material 
to offer a singular reading determining the gradual changes in amplification of the four channels in his set-up. As a continuation of his research on the alteration of tones, Neuhaus modulated four feedback loops here in order to 'multipl[y] the level of complexity enormously' (Neuhaus 2003). As Theodore Strongin, critic in the New York Times, put it the day after a concert in New York in early December 1966: 'This piece was not the kind of electronic music that emanates distantly from the speakers. It felt as though one's own head were part of the feedback circuit' (Neuhaus 2003).

These experiments on feedback are particularly significant in the evolution of Neuhaus's work as they gradually led him on from an interest in the alteration of tone towards the inscription of all sonic production in space. As he wrote: 'It created an oscillating system which encompassed the whole room and everything in it including the audience' (Neuhaus 2003). In effect, as a retroactive phenomenon feedback breaks with the relationship of cause and effect that exists in classic instrumental gesture; its pitch, its volume and its variations depend on many parameters that interact with each other, going from the acoustics of the room to the mass and movements of bodies present in it, through the position of microphones in relation to the speakers.

These first electronic experiments seem, however, retrospectively to have contributed in a way that goes beyond the mere consideration of the inherently in situ nature of the use of feedback in performance. Together with this new attention given to space, electronics, which was to remain Neuhaus's favourite medium, implicitly allowed new relationships to time in the work on sounds. As a looping of an electroacoustic system, feedback allows durations that exceed those of the conventional instrumental gesture, its 'self-sustaining-ness' announcing the continuous sounds generated by electronic devices that he produced later for his Place installations. In a public discussion with Arthur Danto, forty years later, coming back to the reasons for his choice of electronics in his installations, Neuhaus explains that the only practical means to realise a sound work of mine is through electronics. I can't have musicians sitting somewhere twenty-four hours a day like Muzak. A mechanical system has limited sound possibilities and wears out. Over the past thirty years electronic circuitry has offered solutions which allowed me to model sound in a non-physical medium' (Neuhaus 2006).

Other works by Neuhaus on feedback of a different nature (broadcast signal) would also play a role in these developments. In the broadcast piece Public Supply I (1966), Neuhaus opened the WBAI radio waves to exterior sounds during a show, installing ten telephone lines in the radio studio, enabling the public to call in and broadcast any sound over the air. Neuhaus states: ' $[I]$ asked them to leave their radio on while calling so that I would have some different feedbacks to work with' (Neuhaus 1994b). With this work, feedback became in some way 'public', spilling out from the auditorium of a concert hall with its own acoustics, to address itself to any potential listener. Although mixing the sounds in the radio studio, Neuhaus was no longer at the centre of the system, but just one contributor/ performer among others, with each listener-transmitter being able to play with the distance between his/her handset and radio set speaker in the modulation of his/ her own feedback and, above all, the experience being multiplied by the numerous listening points that were activated simultaneously. Through the opening of these telephone lines and the multiplication of feedback, Neuhaus brought about his own withdrawal as a performer (Neuhaus 1994b), in order to understand a sound situation in its multiplicity, without seeking to restrict its perception from a focused point of view. In other words, the experience referred to a certain polycentrism, or to use the words of Daniel Charles about Cage, an 'explosion of all centration' (Charles 2002: 43). In the same year, Neuhaus also designed the small electronic object Max-Feed (1966), produced by MassArt and based, in turn, on a feedback system. The electronic device, developed in the wake of his performances of Fontana Mix, sought, like Public Supply I, to broaden the circle of listeners beyond the regulars attending concert halls programming avant-garde music. It presented itself as an object of live electronic music to be used at home, for personal use on one's own hi-fi, television or radio, in order to transform the sound by turning it into feedback: 'No longer a passive forum for commercial radio, the Max-Feed purchaser's living room was transformed into an indeterminate and phenomenologically activated installation' (Joseph 2009: 70).

Several elements emerged from Neuhaus's work on feedback during the 1960s, work in which a musical concept that went beyond instrumental performance on stage gradually took shape and moved towards sound installation. Whether relationship to place, the sounds sustained, the withdrawal of the ego, the polycentrism, or the renewed relationship with audiences which these experiments instituted, a certain shift took place here in terms of the points of aesthetic interest which occupied the musician, sounding the death knell of his career as a performer specialised in avant-garde music for percussion and opening up a new field of possibilities. Synthesising in his own way the movements at work in this series of decisive experiences, Neuhaus writes:

I began my career as a musician working in a sphere of music where distinctions between composer and performer were beginning to disappear. I became interested in going further and moving into an area where composer and performer would not exist. In the early 1960's, I used acoustic feedback in my stage performances. The room itself would generate the sound, and it was always out of 
my direct control. I gradually adjusted the levels of the amplifier channels until things began to move, but I still had no control whatsoever over the sounds and their movements. [...] It no longer seems necessary for me to do it on stage. I began to understand that I wasn't interested in making musical 'products' but that I did want to be a catalyst for sound activity. (Neuhaus in Zacharopoulos 1987)

\section{ALVIN LUCIER AND THE SPATIAL INTROSPECTION OF FEEDBACK}

The sequence of events was different with Lucier. His interest in live electronic music and feedback originated in his collaborations within the Sonic Arts Union, which he founded with Robert Ashley, Gordon Mumma and David Behrman in 1966. Residing in Ann Arbor since the late 1950s, Ashley and Mumma had set up the Cooperative Studio for Electronic Music, whose activities continued during the first half of the 1960s, with the organisation of an annual event dedicated to experimental and especially electronic music: the ONCE Festival. One year, at the end of a festival to which Behrman and Lucier were invited, the four musicians decided to get together to tour with their respective works. Unlike sets of live electronic music of the same era, such as MEV or AMM, the Sonic Arts Union was not really a band. It was more of a music association, bringing material together and enabling each composer to benefit from the assistance of the other members in the performance of his pieces. As Lucier reminds us: 'We didn't improvise, we didn't collaborate. We simply shared equipment and played in each other's pieces' (Lucier 2012: 71).

The Sonic Arts Union repertoire was very much focused on feedback, which pops up here and there in the compositions of each member, once again often with a view to transforming the tones of instruments or voices, or as a way of reinserting sounds. Thus, in The Wolfman (1964) for amplified voice and tape, Ashley, with a microphone positioned very close to his mouth, used his oral cavity as a sound box of variable size, allowing him to modulate the feedback, progressively and inexorably filling the entire space of the concert hall. Lucier remembers the performances of this piece:

Throughout the piece the volume level is turned up so high that feedback is created between a microphone and loudspeakers positioned around the hall. It left unattended feedback grows and grows to unbearable levels. [...] What he is actually doing is coupling - a small room of variable size (the human mouth) changes to a large one of fixed size (the concert hall). (Lucier 2012: 71-2)

In Behrman's Wave Train (1966), pickups amplified at the threshold of feedback were placed on the strings of a grand piano, so that the feedback vibrated the strings of the instrument. In another relationship to feedback, Mumma, in Hornpipe (1967), walks the stage space with his amplified French horn connected to a Cybersonic Console of his own creation to explore and play with the resonance of the space, reinjecting the sounds captured in the filters of the electronic device until saturation of the circuit.

Several of Lucier's pieces from the late 1960s also have a more or less direct relationship with feedback. In Music for Solo Performer, for enormously amplified brain waves and percussion (1965) - a piece which, according to the composer, constitutes a real turning point in his work in its movement towards experimentation - electrodes were placed on the performer's temples in order to capture the alpha waves generated by the brain in the rest state and transmit them, once amplified, to a network of loudspeakers arranged against a set of percussion instruments that they cause to vibrate. While this is not electroacoustic feedback, the piece nevertheless creates a loop, prefiguring Lucier's interest in feedback. The loop here is of a chain of listening, namely aural feedback: the silent listening of the composer, his eyes closed on stage, facing that of the listeners, stunned by the theatre of ghosts being played out in front of them. In other words, his listening of their attentive listening of his brain activity produces the waves which slowly bring the mute instruments back to life - not in terms of their being played but in the liveness of the acoustic phenomena. As Lucier puts it: 'I had to learn to give up performing to make the performance happen' (Lucier 1995a: 418).

Although not yet electroacoustic feedback, a relationship of reinjection also structures the development of I Am Sitting in a Room (1969). The reading of a text presenting the protocol of the composition was recorded on a tape recorder, the recording then simultaneously recording the acoustics specific to the space. This recording was then immediately re-broadcast in the same space - a broadcast itself recorded to be re-broadcast in turn, etc. With each new recording, the frequencies of resonance of the piece are thus reinforced, while the text gradually becomes less and less intelligible, the recorded voice transforming into a drone magnifying the acoustic signature of the space. As Simon Emmerson notes: 'This is a kind of "time delayed" feedback' (Emmerson 2007: 134).

While Lucier's works of this period frequently use electronics and electroacoustic devices, it should be noted that this choice was partly a matter of pragmatism. Indeed, the electronic medium imposed itself rapidly on the composer, in that it allowed him to reveal the acoustic phenomena that he sought to isolate more clearly. In an interview with Ashley, Lucier explains the reasons for his decision to use sinewaves in a work such as Outlines of Persons and Things (1975), which focuses mainly on the phenomenon of diffraction:

Sounds are too complicated in everyday life: speech, sounds of automobiles, sounds of storms, things like that, 
are too complicated for you to perceive them bounding around yourself or objects. So I try to find a clear, technical way of presenting them by using pure sine waves coming out of loudspeakers that I can control. [...] It's like distilling; making pure those things that happen anyway, but that you don't perceive because they're too complicated. (Lucier in Ashley 2000: 81)

In 1975 Lucier composed a piece literally out of feedback: Bird and Person Dyning. For Thanksgiving, Lucier received a gift mailed by Douglas Kahn. It was a small bird to hang on a Christmas tree that made an electronic chirping. Not knowing what to do with this bird, Lucier took it to his studio and decided to listen to the birdsong using a binaural microphone, a pair of microphones that are placed where the ears are so as to reproduce the stereo sound image of listening. Lucier walked up and down in his studio to examine the propagation of sound emitted by the electronic bird in the space. However, as he explained, that day he had set the amplification of the microphones a bit too high and feedback began to fill the space before he could lower the volume (Lucier 2002: 24). As he was rushing over to do so, he noticed that 'beautiful interference patterns were occurring between the sounds of the birdcall and the strands of feedback. It was an accident. And so then I learnt to control the feedback and to search for places in the room where the feedback is such that it does cause these beautiful phantom images' (Lucier 1995b). There were actually multiple effects because there were the phantom images of the electronic bird in the space as well as the resulting frequencies, effects that were specific to the inner ear and heterodyne effects (which is where the name of the piece came from). Thus the principle behind Bird and Person Dyning was developed: the performer moves in the space with microphones set to feedback and play with the acoustic effects produced by the encounter and the dissemination of feedback and the electronic bird in the space.

In reality there's actually a triple relationship to space here. First, and as the composer says in his accounts of different performances of this piece, the acoustics of space directly influence the sounds produced. At the same time, however, and in connection with this first relationship, sound itself produces space, marking areas and defining territories. As stated in the score, playing Bird and Person Dyning indeed consists in mapping the various pitches and intensities of the sound space that is produced, while at the same time modulating the feedback (Lucier 1995a: 358). To these two relationships is added the relationship of the presence and movements of the perceiving subject, whose spatial location inflects the listening material through a sort of aural feedback. Evoking this piece during an interview with Lucier, Douglas Simon sums it up in these words: 'What you're doing is putting your own sonic perspective back into the room [...] so it becomes part of the room again' (Lucier 1995a: 174).

\section{FEEDBACK: CONSIDERED AS SOUND SPACE AND THE TRANSFORMATION OF LIVENESS}

Feedback experiments were a real source of wonder for both Neuhaus and Lucier and led each of them, incidentally, through their own individual development, to an interest in sound installation. This interest was a result of several factors that emerged directly from the different elements that I have mentioned and that I would now like to bring together.

First there is the importance of space and site-based creation. This is what Max Neuhaus had to say about Fontana Mix - Feed: 'Although the execution of the score is identical in each of these performances, the actual sounds that make up each realisation are completely different as they are determined by which percussion instruments are used, the acoustics of the room and the position of the mikes in relation to the loudspeakers and the instruments at each specific moment' (Neuhaus 2003). Henceforth any work implying this type of feedback can thus only be in situ: it depends upon how sounds wander in space. Feedback thus revealed spatial dimension as an essential feature of sound. Lucier makes this point in a 1979 text entitled The Propagation of Sound in Space, in which he notes that historically sound has mainly been represented as a two-dimensional phenomenon, with pitch (vertical axis) and time (horizontal axis), but that it is actually three-dimensional - the third dimension being space (Lucier 1995a: 416). However space, as Lucier remarks in Bird and Person Dyning, is not static for all that. It also varies according to itineraries and what is within the space. This aspect was to be at the heart of Neuhaus's installations, which always involved circulation through space, linking listening to this circulation in order to capture a site's 'sound topography' (Neuhaus 1994a: 66).

Feedback thus hugs the site and is an expression of it but also varies according to the social activity taking place within it, the movement or stillness of bodies and other displacements inside it. What these works explore, question and highlight are the 'constraints of place' (Gauthier 1987: 30) that condition any work that is exhibited, reflecting the configuration and acoustic, institutional and social conditioning of the exhibition space back on itself. Here I am thinking in particular about Neuhaus's later sound installations, where the artist plays with sounds seeming to merge with those that characterise the site, the ventilation (Untitled, ARC 2 Musée d'Art Moderne de la Ville de Paris, 1983) and heating system (Untitled, Kunsthalle Basel, 1983) or sounds from the external environment (Times Square, New York, 1977-92; 2002-present), producing an interlinking sound space focusing on a problematisation of context. Branden W. Joseph underlines this when writing about Neuhaus's 
so-called Place installation, describing them as 'almost but not quite merging with the sites from which they are nonetheless inextricable and which they provide with an acoustic "halo"' (Joseph 2009: 69).

Another important aspect of these investigations that was previously referred to with regard to the aesthetic issues of live electronic music is that for these artists feedback goes hand in hand with a loss of control, which proves crucial from the perspective of the experience produced. In their writings and interviews, both Lucier and Neuhaus emphasised the euphoria experienced by the loss of control triggered by feedback, which is highly unstable and unpredictable (Lucier 2002; Neuhaus 2003). To a certain extent they no longer controlled the work and it almost became independent of them. They were no longer playing instruments but had set up a self-feeding system, very much like what is produced in a sound installation. It is interesting to note here that Lucier and Neuhaus use almost exactly the same vocabulary to describe this phenomenon. In the booklet accompanying the record Fontana Mix - Feed, Neuhaus wrote: 'The factors here are so complex that even if the piece were to be performed twice in the same room with the same audience, the same instruments, and the same loudspeakers, it would have completely different sound and structures each time. It seems something alive' (Neuhaus 2003, italics mine). As for Lucier, in an article entitled 'My affairs with Feedback', in which he speaks about his feedback piece Small Waves (1997), which also led to the creation of a sound installation, Empty Vessels (1997) he says: 'The feedback resembled a living organism' (Lucier 2002: 25, italics mine).

\section{CONCLUSION: SOUND INSTALLATION AS EMANCIPATION OF LIVENESS}

Reflecting upon Max Neuhaus's and Alvin Lucier's first electronic works on electroacoustic feedback, we are able to consider how their research into live electronic music, meant to be performed on stage, announced a whole other form of creation, which was paradoxically emancipated from the concert hall and essential to the emergence of sound art: sound installations. Indeed, these experiments quickly extended into areas other than research on tone and the live dimension of electronic performances, in order to explore the inscription in space of all propagation of sound. While feedback is not the only reason for Neuhaus and Lucier's interest in sound space and aural topography, there is, here, a shift of attention, initially focused on the sounds produced, to space, mirroring the process, according to Neuhaus, that is produced in his installations, where the shift produced by the experience is from a focus on the sounds to a focus on the context (Neuhaus 1994a: 98).

However, the practice of sound installation does not replace that of live electronic music in the aesthetic development of each artist. Although Neuhaus later abandoned stage performance, the shift in his artistic concerns was a gradual one. For Lucier, installations and compositions quickly came to coexist in his work, the border between them often being rather porous. Lucier does not seem to care much about the categories. As he explains in his article 'Thoughts on Installations': some compositions are transposed into installations (Small Waves becomes Empty Vessels), or conversely some installations give rise to performances, as when making a record for example (Music on a Long Thin Wire, 1977) (Lucier 1995a: 500-11).

But beyond the spatial dimension, which is only one aspect of these works, the last component evoked seems to me to be of particular interest when thinking about the history of the emergence of sound installation, namely the interest in the 'liveness' of the form produced. It may be noted in fact that this liveness, which was so essential for the experiments that these musicians carried out with live electronic music, was not abandoned at all in subsequent sound installations, but was instead extended through them in a singular way. Certainly this attention to liveness takes different forms in the development of the practice of each of these musicians, affecting rather the living character of the sound phenomena themselves in Lucier (Saladin 2015) while being revealed in the attachment to that which constitutes the character of place in Neuhaus (Neuhaus 1995: 111). Neverthless it seems, both simultaneously in their installations and above and beyond their primary preoccupations, to touch another aspect too: the singular relationship to the audience that the sound installation establishes. Talking about his sound installation Empty Vessels, Lucier wrote: 'As visitors walk through the installation the motions of their bodies disturb the strands of feedback causing ripples of sound to occur' (Lucier 2003: 25). Focusing also on the audience's aesthetic experience, Neuhaus observes more generally about his work: 'The moment pieces generate an instant of being in one's own place; place pieces generate a period of being in one's own time' (Neuhaus 1994a: 101). While the historiographies of sound art often consider the emergence of sound installation as an emancipation from concert conditions, maybe, instead, we could see in them a certain emancipation of liveness, where real time, interaction and live experience's fragility and indeterminacy, which were initially so prized by live electronic musicians in their performances on stage, might come together in the very experience of the audience.

\section{REFERENCES}

Ashley, R. 2000. Music with Roots in the Aether. Interviews with and Essays about Seven American Composers. Köln: MusikTexte.

Barthes, R. 1980. New Critical Essays. New York: Hill and Wang. 
Charles, D. 2002. Gloses sur John Cage. Paris: Desclée de Brouwer.

Chion, M. 1982. La musique électroacoustique. Paris: PUF.

Collins, N. (ed.) 2004. Composers Inside Electronics: Music After David Tudor. Leonardo Music Journal 14: 1-4.

Collins, N. 2007. Live Electronic Music. In N. Collins and J. d'Escriván (eds.) The Cambridge Companion to Electronic Music. Cambridge: Cambridge University Press.

Cox, Ch. 2002. The Jerrybuilt Future. The Sonic Arts Union, Once Group and MEV's Live Electronics. In R. Young (ed.) Undercurrents. The Hidden Wiring of Modern Music. New York and London: Continuum and Wire.

Curran, A. 2000. Onoffaboutunderaroundcage. In D. W. Bernstein and Ch. Hatch (ed.) Writings through John Cage's Music, Poetry and Art. Chicago: University of Chicago Press.

Davies, H. 2002. Sound Heard. Chelmsford: Soundworld.

De la Motte-Haber, H. (ed.) 1999. Klangkunst. Tönende Objekte und Klingende Räume. Laaber: Laaber-Verlag.

Deleuze, G. and Guattari, F. 1975. Kafka. Pour une littérature mineure. Paris: Minuit.

Emmerson, S. 2007. Living Electronic Music. Aldershot: Ashgate.

Gallet, B. 2005. Composer des étendues. L'art de l'installation sonore. Genève: HEAD.

Gauthier, M. 1987. Les contraintes de l'endroit. Bruxelles: Les Impressions Nouvelles.

Hacking, I. 2002. L'émergence de la probabilité [Foreword to the French Edition]. Paris: Seuil.

Joseph, B. W. 2009. An Implication of an Implication. In L. Cooke and K. Kelly (ed.) Max Neuhaus, Times Square, Time Piece Beacon. New Haven and London: Dia Art Foundation/Yale University Press.

Labelle, B. 2006. Background Noise. Perspectives on Sound Art. New York: Continuum.

Licht, A. 2007. Sound Art. Beyond Music, Between Categories. New York: Rizzoli.

Licht, A. 2009. Sound Art: Origins, Development and Ambiguities. Organised Sound 14(1): 3-10.

Lucier, A. 1995a. Reflections. Interviews, Scores, Writings, 1965-1994. Köln: MusikTexte.

Lucier, A. 1995b. Interview by M. Parsons. Beats That Can Push Sugar. London Musicians Collective. www.l-m-c. org.uk/texts/lucier.html (accessed 15 April 2005).

Lucier, A. 2002. My Affairs with Feedback. Resonance 9(2): 24-25.

Lucier, A. 2003. Empty Vessels (Tokyo). In M. Hatanaka and S. Shiba (ed.) Sounding Spaces - 9 Sound Installations. Tokyo: NTT Publishing.

Lucier, A. 2012. Music 109 Notes on Experimental Music. Middletown: Wesleyan University Press.
Musica Elettronica Viva (MEV). 1968. Press Kit Booklet. http://musicaelettronicaviva.blogspot.com (accessed 28 June 2008).

Neuhaus, M. 1974. Program Notes. Toronto: York University.

Neuhaus, M. 1994a. Sound Works. Volume I. Inscription. Ed. G. des Jardins. Ostfildern-Stuttgart: Cantz.

Neuhaus, M. 1994b. The Broadcast Works and Audium. In Zeitgleich: The Symposium, the Seminar, the Exhibition. Vienna: Triton. www.max-neuhaus.info/bibliography (accessed 25 November 2016).

Neuhaus, M. 1995. Evocare l'udibile/Évoquer l'auditif. Nice, Castello di Rivoli and Milan: Villa Arson, Museo d'arte contemporanea and Edizioni Charta.

Neuhaus, M. 2003. Liner notes to Fontana Mix - Feed (Six Realizations of John Cage). Milan: Alga Marghen, plana-N 18NMN.44.

Neuhaus, M. 2004. Liner notes to The New York School (Nine Realizations of Cage, Feldman, Brown). Milan: Alga Marghen, plana-N 22NMN.053.

Neuhaus, M. 2006. Max Neuhaus' Conception of a Sound Sculpture. Discussion with Max Neuhaus. In G. Seel (ed.) End of Art-Endings in Art. Basel: Schwabe.

Nyman, M. 1999. Experimental Music. Cage and Beyond, 2nd edn. Cambridge: Cambridge University Press.

Ouzounian, G. 2008. Sound Art and Spatial Practices: Situating Sound Installation Art Since 1958. PhD diss., University of California.

Ouzounian, G. 2013. Sound Installation Art: From Spatial Poetics to Politics, Aesthetics to Ethics. In G. Born (ed.) Music, Sound and Space. Transformations of Public and Private Experience. Cambridge: Cambridge University Press.

Pousseur, H. 1970. Fragments théoriques I sur la musique expérimentale. Études de sociologie de la musique. Brussels: Éditions de l'Institut de Sociologie Université Libre de Bruxelles.

Rogalsky, M. 2013. Booklet for The Art of David Tudor (7 CD box set). New York: New World Records. 80737-2.

Saladin, M. 2015. Laisser les phénomènes être eux-mêmes: l'expérimentation naturaliste d'Alvin Lucier. Analyse musicale 76: 27-33.

Toop, D. 2002. Frame of Freedom. Improvisation, Otherness and the Limits of Spontaneity. In R. Young (ed.) Undercurrents. The Hidden Wiring of Modern Music. New York and London: Continuum and Wire.

Wolff, Ch. 1998. Cues, Writings \& Conversations. Köln: MusikTexte.

Zacharopoulos, D. 1987. Max Neuhaus. Locminé: Edition du Centre d'Art. 